\title{
Percutaneous Fixation of Comminuted Fractures of the Humerus: Initial Experience at Al Razi Hospital, Kuwait
}

\author{
Wieslaw Pospula Tarek Abu Noor \\ Department of Orthopedics, Al Razi Hospital, Kuwait
}

\section{Key Words}

Fracture of the humerus - Percutaneous fixation

\begin{abstract}
Objective: To present initial experience of 12 cases of percutaneous plating of the comminuted fractures of the humerus using minimal access surgery and standard low-contact dynamic compression plate. Patients and Methods: Twelve patients (11 males and 1 female) with an average age of 29.8 years (range 17-46 years) with comminuted diaphyseal fractures of the humerus were treated by minimal access surgery using standard AO/ASIF implants. Fracture was reduced indirectly either by manipulation or by a femoral distractor. Image intensifier was used to monitor the reduction and fixation. The plate was fixed on the anterior surface of the humerus using proximal and distal minimal incision on the anterior aspect of the upper arm. Results: All fractures were united, and all patients had a good range of motion in the adjacent joints. In 1 patient, there was a transient neurological deficit. Conclusion: Percutaneous fixation of comminuted fractures of the humeral shaft is an alternative to standard open surgery, reducing the surgical impact and giving an excellent functional result.

Copyright $\odot 2006$ S. Karger AG, Basel
\end{abstract}

\section{Introduction}

Minimal access surgery as an alternative to standard open reduction and fixation has been increasingly used in treatment of comminuted diaphyseal and articular fractures $[1,2]$. The benefit of minimizing the surgical trauma to the soft tissue and bone and reduction of blood transfusions necessary during the procedure justified imperfection in anatomical alignments of fragments. Although there are several studies on this technique used in the lower extremity $[3,4]$, there are few reports regarding this technique in the comminuted diaphyseal fractures of the humerus $[5,6]$. We present our initial experience of using percutaneous plating of comminuted diaphyseal fractures of the humerus in Al Razi Hospital, Kuwait.

\section{Patients and Methods}

Between 2001 and 2005, 12 patients with comminuted diaphyseal fractures of the humerus were treated by minimal access plating. There were 11 males and 1 female with an average age of 29.8 years (range 17-46 years; table 1). Fractures were classified according to the AO/ASIF fracture classification system [7]. The fracture was reduced under an image intensifier using manipula-

\section{KARGER}

Fax +4161306 1234

E-Mail karger@karger.ch

www.karger.com
Wieslaw Pospula, MD, PhD

Al Razi Orthopedic Hospital

PO Box 4235

Safat 13043 (Kuwait)

Tel. +965 986 2485, Fax +965 482 2240, E-Mail pospulawieslaw@hotmail.com 

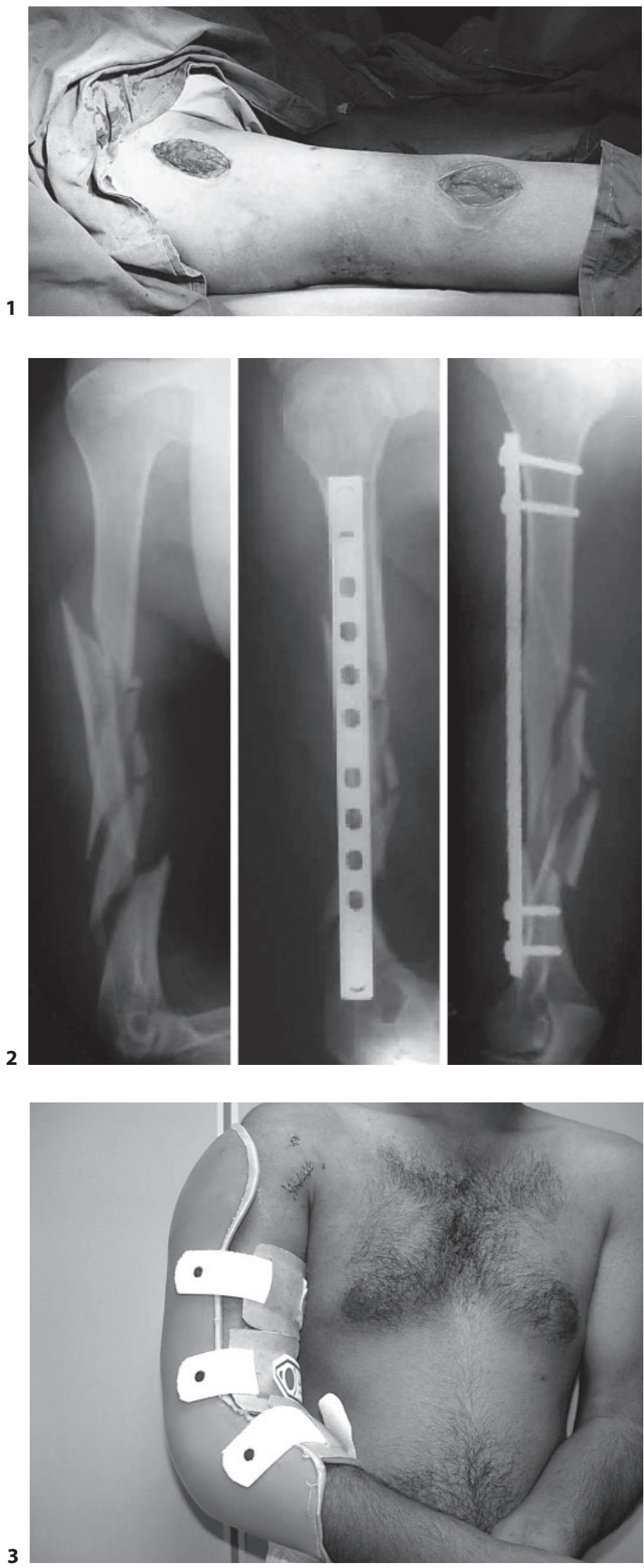

Med Princ Pract 2006;15:423-426 tion or a femoral distractor. The bone was accessed from a small anterior opening, and the long plate was gently passed by blunt dissection over the bone surface until the attachment of the pectoralis major muscle. Next, another channel over the bone surface was made anteriorly from the small opening over the proximal humerus and connected with the previous channel (fig. 1). The plate was then passed across the comminuted area under radiological control, and 2-3 screws were fixed proximally and distally according to the local situation (fig. 2). In all cases except one where broad standard dynamic compression plate was used, standard broad low-contact dynamic compression plate was the method of choice. The wounds were closed and a simple sling was applied. In the first 3 cases, a brace was used (fig. 3), whereas in the remaining cases, only a sling was applied and gentle active movements were encouraged. All patients were followed up in 3-week intervals and when callus appeared, physiotherapy and more active exercises were started. In case No. 3 , the fixation was reinforced by 2 additional screws from the same proximal incision, 2 days after index operation because of shattering of the distal cortex in one of the proximal screws, which was recognized after surgery. In case No. 8 the percutaneous plating was used as a conversion of external to internal fixation without an intermdiate period of plaster immobilization. Alignment, range of movement of the shoulder and the elbow were assessed at the final examination.

Table 1. Patient characteristics, time of union and range of motion

\begin{tabular}{rlllll}
\hline $\begin{array}{c}\text { Case } \\
\text { No. }\end{array}$ & $\begin{array}{l}\text { Age } \\
\text { years }\end{array}$ & Gender & $\begin{array}{l}\text { Union } \\
\text { time } \\
\text { weeks }\end{array}$ & $\begin{array}{l}\text { Shoulder } \\
\text { range of } \\
\text { motion }\end{array}$ & $\begin{array}{l}\text { Elbow range of } \\
\text { motion (flexion/ } \\
\text { extension/ } \\
\text { hyperextension) } \\
\text { degrees }\end{array}$ \\
\hline 1 & 34 & F & 15 & full & $130 / 0 / 0$ \\
2 & 25 & M & 13 & full & $130 / 0 / 15$ \\
3 & 29 & M & 13 & full & $110 / 10 / 0$ \\
4 & 27 & M & 16 & full & $130 / 0 / 0$ \\
5 & 17 & M & 14 & full & $115 / 10 / 0$ \\
6 & 40 & M & 12 & full & $120 / 10 / 0$ \\
7 & 46 & M & 12 & full & $130 / 0 / 0$ \\
8 & 24 & M & 13 & full & $120 / 0 / 0$ \\
9 & 43 & M & 14 & full & $120 / 0 / 0$ \\
10 & 27 & M & 15 & full & $115 / 10 / 0$ \\
11 & 22 & M & 12 & full & $120 / 0 / 0$ \\
12 & 27 & M & 14 & full & $115 / 5 / 0$ \\
\hline
\end{tabular}

Fig. 1. View of intraoperative situation with proximal and distal incision on the anterior aspect of the upper arm (case No. 2).

Fig. 2. Preoperative and postoperative view of the humerus fixed with the technique of minimal access (case No. 1).

Fig. 3. Patient with humeral brace (case No. 3). 


\section{Results}

All fractures were united, with all patients having a good range of motion in the adjacent joints (table 1). Axial and rotational malalignment did not exceed $15^{\circ}$. In case No. 1, transient radial nerve palsy was observed, which resolved 3 weeks after surgery. In case No. 3 with a segmental fracture, solid union occurred at both levels within a period of 3.5 months (fig. 4,5 ).

\section{Discussion}

Treatment of humeral shaft fracture remains a subject of debate. Although conservative treatment may be successful in most cases, several surgical options have been proposed [8-10]. Different types of fixation are in use, including plates, intramedullary locked nails, and external fixation. It is still not obvious which of the surgical modalities is better; however, more evidence that the plate is superior to the nail is found in the literature [1113]. In the last decade, minimal access surgery has been introduced in many surgical specialties. In orthopedic trauma, biological plating is gradually finding its place in the armamentarium of the trauma surgeon [14]. Minimally invasive plate osteosynthesis has been introduced to minimize dissection of broken bone fragments thereby preserving vascularity and healing potential [1]. Biological plating is in common use in the fixation of comminuted diaphyseal fractures of the femur and tibia $[3,4]$. In the fracture of the humeral shaft, percutaneous plating is less popular because of the risk of injury to the neurovascular structures and the radial nerve in particular. Anatomical studies and dissections show that the anterior surface of the humeral shaft and anterior approach is safest for the passage of the plate without risk of damage or need to visualize neurovascular structures $[6,10$, 15]. The surgical technique used, an anterior submuscular approach, proved safe and effective with a low rate of complications. The anterior approach to the humeral shaft has been reported in two studies $[16,17]$. The idea of helical implants of the humerus has been suggested, but these implants are not popular $[6,10]$. On the other hand, to us a twisted plate seems inadequate to assure stable fixation of a comminuted fracture. The length of the implant is directly related to its stability $[18,19]$, therefore the longer the plate, the more stable the fixation. The intramedullary nail has been found to be more mechanically resistant than the plate in experimental study; however, in clinical application, more complications with
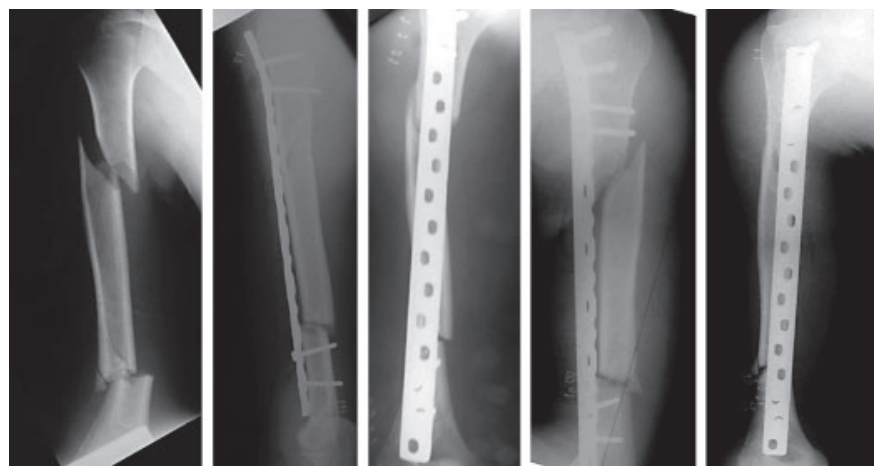

Fig. 4. Preoperative, postoperative and intermediate X-ray of the fracture fixed with the minimal access technique (case No. 3).
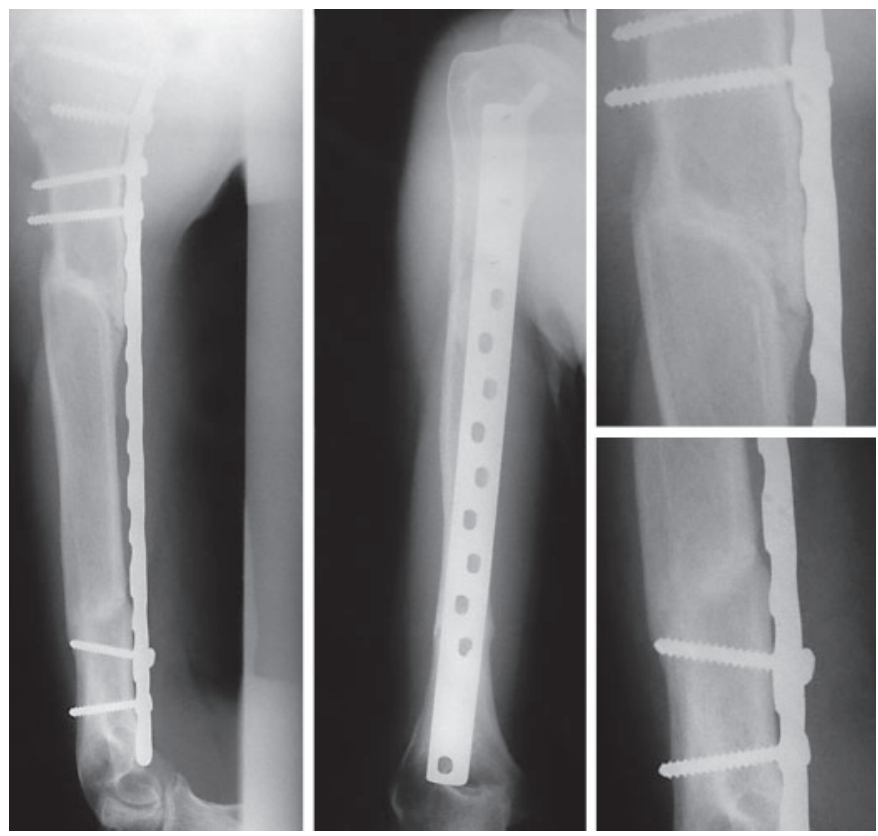

Fig. 5. Final X-ray and close-up view of the united fracture in the same case (No. 3).

the nail have been reported $[11,13,20]$. In our practice, in most cases only 2 screws were used proximally and distally, and there was not a single case of metal failure or loss of fixation. An essential factor in good screw purchase is youth, and indeed all our patients were in the young range of the age group (table 1) with good bone quality. We believe that in this type of fixation, union occurs before the implant can become loose because of the preserved good vascularity of fragments. In case No. 3, with a segmental fracture, solid union (fig. 4,5 ) occurred 
at both levels within a reasonable period although such fractures are known to have a tendency for delayed union [21]. In the patient with radial nerve palsy (case No. 1), a probable explanation is that it was due to excessive manipulation to achieve acceptable alignment. In subsequent cases, reduction was achieved by a temporary external fixator, or displaced fragments were left in place undisturbed. With new minimally invasive plate osteosynthesis instruments, it is hoped that most of the problems associated with reduction will be overcome.

\section{Conclusion}

Percutaneous plating of comminuted fractures of the humeral diaphysis using two small incisions and standard low-contact dynamic compression plate gives an excellent clinical and radiological result with sound union and no complications. It is a useful alternative to other methods of fixation.

\section{References}

1 Perren SM: Evolution of the internal fixation of long bone fractures. The scientific basis of biological internal fixation: choosing a new balance between stability and biology. J Bone Joint Surg Br 2002;8:1093-1110.

$\longrightarrow 2$ Sommer C, Bereiter H: Actual relevance of minimal invasive surgery in fracture treatment. Ther Umsch 2005;62:145-151.

-3 Pospula W, Abu Al Noor T, Ezzat F, Abdul Malak F: Percutaneous fixation of comminuted fractures of the femur and tibia. Preliminary study. Med Princ Pract 2003;12: 214-217.

-4 Kesemenli C, Subasi M, Necmioglu S, Kapukaya A: Treatment of multifragmentary fractures of the femur by indirect reduction (biological) and plate fixation. Injury 2002;33: 691-699.

5 Fernandez Dell'Oca AA: The principle of helical implants. Unusual ideas worth considering. Injury 2002;33(suppl 1):11-27.

6 Apivatthakakul T, Arpornchayanon O, Bavornratanavech S: Minimally invasive plate osteosynthesis (MIPO) of the humeral shaft fracture. Is it possible? A cadaveric study and preliminary report. Injury 2005 ; 36:530-538.

7 Mueller ME: Comprehensive Classification of Fractures. Davos, AO/ASIF Documentation Center, 1966.
8 Sarmiento A, Waddell JP, Latta LL: Diaphyseal humeral fractures: treatment options. Instr Course Lect 2002;51:257-269.

$\checkmark 9$ Schittko A: Humeral shaft fractures. Chirurg 2004;75:833-846.

10 Gardner MJ, Griffith MH, Lorich DG: Helical plating of the proximal humerus. Injury 2005;36:1197-1200.

11 Chapman JR, Henley MB, Agel J, Benca PJ Randomized prospective study of humeral shaft fracture fixation: intramedullary nails versus plates. J Orthop Trauma 2000;14:162166.

12 Ajmal M, O’Sullivan M, McCabe J, Curtin $\mathrm{W}$ : Antegrade locked intramedullary nailing in humeral shaft fractures. Injury 2001;32: 692-694.

13 Niall DM, O’Mahony J, McElwain JP: Plating of humeral shaft fractures - Has the pendulum swung back? Injury 2004;35:580-586.

14 Krettek C, Muller M, Miclau T: Evolution of minimally invasive plate osteosynthesis (MIPO) in the femur. Injury 2001;32(suppl 3):SC14-SC23.

15 Bono CM, Grossman MG, Hochwald N, Tornetta P: Radial and axillary nerves. Anatomic considerations for humeral fixation. Clin Orthop 2000;373:259-364.
16 Livani B, Belangero WD: Bridging plate osteosynthesis of humeral shaft fractures. Injury 2004;35:587-595.

17 Xie X, Ye S, Lin H, Jiang W, Luo Q: The treatment of middle and lower thirds fractures of humerus by anterior plate fixation. Zhongguo Xiu Fu Chong Jian Wai Ke Za Zhi 2005; 19:195-197.

18 Karnezis IA: Biomechanical considerations in 'biological' femoral osteosynthesis: an experimental study of the 'briging' and 'wave' plating technique. Arch Orthop Trauma Surg 2000;120:272-275.

19 Karnezis IA, Miles AW, Cunningham JL, Learmouth ID: Biological internal fixation of long bone fractures. A biomechanical study of a noncontact plate system. Injury 1998;29:689-695.

20 Chen AL, Joseph TN, Wolinksy PR, Tejwani NC, Kummer FJ, Egol KA, Koval KJ: Fixation stability of comminuted humeral shaft fractures: locked intramedullary nailing versus plate fixation. J Trauma 2002;53:733737.

21 Bonnevialle P, Cariven P, Bonnevialle N, Mansat P, Martinel V, Verhaeghe L, Mansat M: Segmental tibia fractures: a critical retrospective analysis of 49 cases. Rev Chir Orthop Reparatrice Appar Mot 2003;89:423432 